\title{
Cognitive Skills Achievement in Mathematics of the Elementary Pre-Service Teachers Using Piaget's Seven Logical Operations
}

\author{
Jaynelle G. Domingo 1 , Edwin D. Ibañez ${ }^{2}$, Gener S. Subia ${ }^{3 *}$, Jupeth T. Pentang ${ }^{4}$, Analyn M. \\ Gamit $^{5}$, Lorinda E. Pascual ${ }^{6}$, Jennilyn C. Mina ${ }^{7}$, Arlene V. Tomas ${ }^{8}$, Minnie M. Liangco 9
}

Faculty, Nueva Ecija University of Science and Technology (NEUST) ${ }^{1,5,6,7}$

Faculty, Central Luzon State University(CLSU) ${ }^{2}$

Faculty, Western Philippines University (WPU) ${ }^{4}$

Faculty, Tarlac Agricultural University (TAU) ${ }^{8}$

Faculty, Pampanga State Agricultural University (PSAU) ${ }^{9}$

Faculty, Wesleyan University Philippines, (WUP) ${ }^{3 *}$ subiagener@yahoo.com

Article History: Received:11 January 2021; Accepted: 27 February 2021; Published online: 5 April 2021

\begin{abstract}
This study determined the cognitive skills achievement in mathematics of elementary pre-service teachers as a basis for improving problem-solving and critical thinking which was analyzed using Piaget's seven logical operations namely: classification, seriation, logical multiplication, compensation, ratio and proportional thinking, probability thinking, and correlational thinking. This study utilized an adopted Test on Logical Operations (TLO) and descriptive research design to describe the cognitive skills achievement and to determine the affecting factors. Overall, elementary pre-service teachers performed with sufficient understanding in dealing with the TLO. However, in each logical operation, students were found to have insufficient understanding of probability thinking and correlational thinking. These insufficiencies in other logical operations were attributed to their misconceptions on some mathematical terms, misinterpretation of the problems, poor comprehension skills, poor problem-solving skills, and poor performance in mathematics in general.
\end{abstract}

Keywords-Achievement in Mathematics, cognitive skills, education, elementary pre-service teachers, Piaget's logical operations

\section{INTRODUCTION}

Cognitive skills achievement in mathematics as the quantified measure of the cognitive skills that an individual can perform in mathematics serves as a basis in determining the mathematics ability of the Filipino learners [1]; [2]. Cognitive skills are any mental skills that are used in the process of acquiring knowledge which includes reasoning, perception, and intuition [3]. In the well-known theory of cognitive development proposed by famous French-Swiss psychologist Jean Piaget, he discussed the stages of development and the cognitive skills and intelligence learned by children in a particular stage. He defined cognitive development as the mental growth or development of the intelligence of the learner.

Along with the implementation of the $\mathrm{K}$ to 12 Curriculum is the update in the conceptual framework of mathematics education. The twin goals of mathematics education in the country are problem-solving and critical thinking as indicated in the $\mathrm{K}$ to 12 Curriculum Guide (CG) for mathematics in basic education. The CG also emphasizes that the twin goals are to be achieved with organized and rigorous curriculum content, a well-defined set of high-level skills and processes, desirable values and attitudes, and appropriate tools, considering the different contexts of Filipino learners. "As a guide to belief and action, critical thinking is the intellectually disciplined method of actively and skillfully conceptualizing, applying, analyzing, synthesizing, and/or assessing knowledge gathered from, or produced by observation, experience, reflection, reasoning, or communication" [4]. Several definitions of critical thinking have become known from the cognitive psychological approach which includes mental processes, strategies, and representations people use to solve problems, make decisions, and learn new concepts [5]; [6]; [7]. On the other hand, [8] defined problem solving as finding a way around a difficulty, around an obstacle, and finding a solution to a problem that is unknown. [9] stressed that problem solving is a critical and higher level of cognitive skills.

In the aforementioned definitions of critical thinking and problem-solving, cognitive skills are associated and needed to improve the said twin goals of mathematics education. The acquisition of cognitive and process skills and 
age is the basis of cognitive development theory and its stages. The sensorimotor stage, pre-operational stage, concrete operational stage, and formal operational stage are the four phases of cognitive growth according to this theory. Learning, according to Piaget, is a process of evolving cognitive frameworks, which are structured hierarchically as the structures become more complex. [10] described this hierarchy that when a child is in a particular stage, this child can perform specific cognitive skills. These stages of intellectual development particularly in the two later stages, as presented in his books [3]; [11], are characterized by seven logical operations, namely: classification, seriation, logical multiplication, compensation, ratio and proportional thinking, probability thinking, and correlational thinking.

Ideally, college students particularly the elementary pre-service teachers are in the formal stage of cognitive development according to Piaget's theory. They should be able to value mathematics, solve problems, and develop confidence [12]. The seven logical operations are expected to be developed among them. As teachers and as future teachers of mathematics at the elementary level, they should have sufficient skills and knowledge to enable their students to achieve the expected mathematics competency defined by $\mathrm{K}$ to 12 content standards as required by higher education [13].

With the spirit of honing the pre-service elementary teachers and developing the cognitive skills among them, it is imperative to determine if the process skills and the logical operations are already developed in them. This study was conducted to discern the cognitive skills achievement in Mathematics of the elementary pre-service teachers using Piaget's seven logical operations.

\section{METHODOLOGY}

The study used a descriptive research template with a questionnaire to explain elementary pre-service teachers' cognitive skills achievement in basic mathematics. Descriptive research design is a method for collecting, evaluating, classifying, and tabulating data about current situations, behaviors, attitudes, procedures, patterns, and cause-and-effect relationships, and then making adequate and reliable interpretations of the data using or without statistical methods [14].

The study's purposively chosen respondents were 88 elementary pre-service teachers enrolled in one of Nueva Ecija's colleges of education. Purposive sampling design, also known as judgmental sampling, is a deliberate sampling technique in which the researcher selects the respondents who best meet the study's objectives [15]. The Test on Logical Operations, developed by [12], was used in this study as an adopted and validated teacher-made test questionnaire (TLO). The performance and categorization of cognitive skills based on their cognitive skills achievement in mathematics were described using descriptive statistics such as frequency, percentage, mean, and rank.

\section{RESULTS AND DISCUSSION}

\section{Respondents' Cognitive Skills Achievement in Mathematics}

To address the first objective of the study, the performance of the respondents in each logical operation was gathered and analyzed in order to determine their level of understanding. The multiple-count scoring scheme proposed by [16] was used to determine the qualitative description for each performance. The respondents of the study who were chosen purposively were 88 elementary pre-service teachers enrolled in one of the colleges of Education in Nueva, Ecija. "Purposive sampling design also known as judgmental sampling is a deliberate sampling technique where the researcher uses his good judgment in selecting the respondents who best meet the purposes of the study" [15]. This study used an adapted and validated teacher-made test questionnaire developed by [12] called the Test on Logical Operations (TLO). Descriptive statistics such as frequency, percentage, mean, and rank were employed to describe the performance and categorization of cognitive skills based on their cognitive skills achievement in mathematics. 
Jaynelle G. Domingo ${ }^{1}$, Edwin D. Ibañez ${ }^{2}$, Gener S. Subia ${ }^{3 *}$, Jupeth T. Pentang ${ }^{4}$, Analyn M.

Gamit $^{5}$, Lorinda E. Pascual ${ }^{6}$, Jennilyn C. Mina ${ }^{7}$, Arlene V. Tomas ${ }^{8}$, Minnie M. Liangco ${ }^{9}$

Table 1. The respondents' cognitive skills achievement in mathematics

\begin{tabular}{lccc}
\hline \hline \multicolumn{1}{c}{ LOGICAL OPERATIONS } & $\overline{\mathbf{x}}$ & $\begin{array}{c}\text { LEVEL OF } \\
\text { UNDERSTANDING }\end{array}$ & RANK \\
\hline Classification & 10.82 & Sufficient & 3 \\
Seriation & 10.15 & Sufficient & 5 \\
Logical Multiplication & 14.69 & Sufficient & 1 \\
Compensation & 13.83 & Sufficient & 2 \\
Ratio and Proportional Thinking & 10.51 & Sufficient & 4 \\
Probability Thinking & 6.30 & Insufficient & 7 \\
Correlational Thinking & 8.93 & Insufficient & 6 \\
Global Mean Score & 10.74 & Sufficient & \\
\hline \hline
\end{tabular}

The results shown in Table 1 revealed that in general, the respondents showed sufficient understanding in all the seven logical operations of Piaget with a global mean score of 10.74. Rank one in the seven logical operations as the highest achieved score with a sufficient level of understanding was the logical multiplication $\left(\mathrm{x}^{-}=14.69\right)$. This meant that the respondents could demonstrate or perform the expected standard logical operations, especially multiplication operations involving, or being in accordance with logic. Compensation, counterbalancing, creating, or providing sufficient equivalence were the next steps, as the second highly achieved logical operations $\left(\mathrm{x}^{-}=13.83\right)$ with a sufficient level of understanding. The third was the classification with a mean score of 10.82 and level of understanding as sufficient. Moreover, respondents also showed sufficient understanding in ratio and proportional thinking $\left(\mathrm{x}^{-}=10.51\right)$ and seriation $\left(\mathrm{x}^{-}=10.15\right)$. However, Table 1 also revealed alarming results as the respondents performed with insufficient understanding both in probability thinking $\left(\mathrm{x}^{-}=6.30\right)$ and correlational thinking $\left(x^{-}=8.93\right)$. Correlational thought refers to the establishment of a connection or causal association, while probability thinking refers to the establishment of a logical relation statement such that proof conforming to one conforms to the other to some degree [10]. It may also refer to the presentation or laying out of information in order to demonstrate relationships [17]. This means that in these two logical operations, the respondents, in general, just interpreted the problem correctly and made an overt and partial explanation of the solution of the problem.

The results presented in Table 2 confirmed the results of [18] in five logical operations namely: classification, seriation, logical multiplication, compensation and ratio and proportional thinking where the respondents performed with at least sufficient understanding in answering but not in probability thinking and correlational thinking. However, the findings were in contrast with the results of [19] and [12] particularly in the said first five logical operations where both respondents of the two previous studies showed insufficient understanding.

\section{Respondents' Category of Cognitive Skills}

To address the second objective of this study, this portion presents the frequency and the percentage of the respondents who were categorized based on their cognitive skills achievement in mathematics. The categorization of the respondents was proposed by [20]. Student participants, in general, were in the age range of 19-20 years old, which according to Piaget's theory of cognitive development were on their formal operational stage. Part of this study concurs with Piaget.

The majority of respondents ( 52 or 59.09 percent) were in the formal operational stage, according to the data in Table 2. Three respondents $(3.41 \%)$ were in the late formal stage, suggesting that these three elementary pre-service teachers thoroughly and correctly solved almost all of the logical operational problems, according to [21]. They showed strong evidence of systematic attainment of critical thinking and reasoning patterns in mathematics, and they clearly expressed their thought processes by presenting correct answers the majority of the time. They were also able to show that they had a broad understanding of the problem, that they used a cognitive schema to help them understand the problem structure, that they selected and used effective solution methods, and that they got the right answer.

Meanwhile, the majority of the respondents (49 or 55.68\%) were at the early formal stage of Piaget's Theory of Cognitive Development. This suggested that the majority were able to make considerable progress with their solutions, with problems on all logical operations nearly solved and solutions that were correct but contained slight errors on all test products. At the formal level, there were some indications of the attainment of reasoning trends in mathematics. Their thought processes were evident in the problem approach they provided.

However, 36 or 40.91 percent of the respondents did not concur with Piaget. These 36 respondents were considered at the late concrete operational stages which age ranges from 7 to 11 years old. This showed that these students had a 
good understanding of the problems posed by the representations for and logical operation and had made early attempts to solve all of the problems. Their solutions and responses were fraught with contradictions. As a result, they were successful in achieving the sub-goal but failed to achieve the problem's main goal [21].

Table 2. The Respondents' Categories of Cognitive Skills Based on their Achievement in Mathematics

\begin{tabular}{ccccccc}
\hline LOGICAL & \multicolumn{2}{c}{ LATE CONCRETE } & \multicolumn{2}{c}{ EARLY FORMAL } & \multicolumn{2}{c}{ LATE FORMAL } \\
\cline { 2 - 7 } OPERATIONS & Mean & $\begin{array}{c}\text { Level of } \\
\text { Understanding }\end{array}$ & Mean & $\begin{array}{c}\text { Level of } \\
\text { Understanding }\end{array}$ & Mean & $\begin{array}{c}\text { Level of } \\
\text { Understanding }\end{array}$ \\
\hline Classification & 10.86 & Sufficient & 11.22 & Sufficient & 13.33 & Sufficient \\
$\quad \begin{array}{c}\text { Seriation } \\
\text { Logical }\end{array}$ & 8.72 & Insufficient & 11.08 & Sufficient & 12.00 & Sufficient \\
$\begin{array}{c}\text { Multiplication } \\
\text { Compensation }\end{array}$ & 12.67 & Sufficient & 16.00 & Complete & 17.67 & Complete \\
$\quad \begin{array}{l}\text { Ratio and } \\
\text { Proportional }\end{array}$ & 12.28 & Sufficient & 14.71 & Sufficient & 18.00 & Complete \\
$\begin{array}{c}\text { Thinking } \\
\text { Probability }\end{array}$ & 8.47 & Insufficient & 11.61 & Sufficient & 17.00 & Complete \\
$\begin{array}{c}\text { Thinking } \\
\text { Correlational } \\
\text { Thinking }\end{array}$ & 4.22 & Insufficient & 7.29 & Insufficient & 15.00 & Sufficient \\
\hline
\end{tabular}

As 36 or 40.91 of the respondents were considered in the late concrete, they were able to show sufficient understanding in logical multiplication $\left(\mathrm{x}^{-}=12.57\right)$, compensation $\left(\mathrm{x}^{-}=12.28\right)$, and classification $\left(\mathrm{x}^{-}=10.86\right)$. Meanwhile, they performed insufficiently in probability thinking $\left(\mathrm{x}^{-}=4.22\right)$, correlational thinking $\left(\mathrm{x}^{-}=6.72\right)$, ratio and proportional thinking $\left(\mathrm{x}^{-}=8.47\right)$, and seriation $\left(\mathrm{x}^{-}=8.72\right)$. With a global mean score of 9.13 , this group of students showed a lack of comprehension of all logical operations.

Early formal students $(n=49)$ answered the problems in logical multiplication $\left(\mathrm{x}^{-}=16.00\right)$ with complete understanding. They showed sufficient understanding in answering problems in compensation $\left(\mathrm{x}^{-}=14.71\right)$, ratio and proportional thinking $\left(\mathrm{x}^{-}=11.61\right)$, classification $\left(\mathrm{x}^{-}=11.22\right)$, and seriation $\left(\mathrm{x}^{-}=11.08\right)$. However, they had an insufficient understanding of probability thinking $\left(\mathrm{x}^{-}=7.29\right)$ and correlational thinking $\left(\mathrm{x}^{-}=9.96\right)$. This group of students had sufficient understanding in solving the problems in the seven logical operations with a global mean score of 11.70 .

The only three students who were considered in the late formal stage performed with complete understanding in correlational thinking $\left(x^{-}=18.67\right)$, compensation $\left(x^{-}=18.00\right)$, logical multiplication $\left(x^{-}=17.67\right)$ and ratio and proportional thinking $\left(\mathrm{x}^{-}=17.00\right)$. This meant that they had the capabilities and potentials regarded as beyond what was expected of them. They showed a complete understanding of the essence and structural relations of data in the problem. Also, they exhibited this characteristic, they had the ability to understand and grasp fully the mathematical tasks presented to them and solved them with logical representations [18]. Meanwhile, they performed sufficiently in probability thinking $\left(\mathrm{x}^{-}=15.00\right)$, classification $\left(\mathrm{x}^{-}=13.33\right)$, and seriation $\left(\mathrm{x}^{-}=12.00\right)$. With these results, the three respondents committed minor mistakes and were expected to be able to deal with and perform higher order of difficulty. The results of this study negated the study of [19], [22], [12], and [21] were the result of their studies were alarming to reveal that most of their respondents were considered at the concrete operational stage. This study apparently sounded positive since the majority (52 or 59.09\%) were able to perform the logical operations. This concurred with [18] where 12 out of 12 of his respondents were at the formal stage of cognitive development. Generally, the respondents of this study proved that the expected stage as students at a higher level matched with Piaget's theory.

\section{CONCLUSIONS AND RECOMMENDATION}

Based on the findings of this study, the following conclusions were drawn. Elementary pre-service teachers showed sufficient understanding in most of the seven logical operations and insufficient to some. However, they showed an insufficient understanding of probability thinking and correlational thinking. These insufficiencies in other logical operations were attributed to their misconceptions on some mathematical terms, misinterpretation of the problems, poor comprehension skills, poor problem-solving skills, and poor performance in mathematics in general. Furthermore, the cognitive skills achievement of the majority of elementary pre-service teachers can be considered formal. However, this result is still alarming for these groups of students who would be deployed to teach the young learners. A higher percentage or ideally, all of them are expected in the late formal where the 
Jaynelle G. Domingo ${ }^{1}$, Edwin D. Ibañez ${ }^{2}$, Gener S. Subia ${ }^{3 *}$, Jupeth T. Pentang ${ }^{4}$, Analyn M.

Gamit $^{5}$, Lorinda E. Pascual ${ }^{6}$, Jennilyn C. Mina ${ }^{7}$, Arlene V. Tomas ${ }^{8}$, Minnie M. Liangco ${ }^{9}$

cognitive skills are performed with mastery as they will transfer knowledge and teach skills. Students in the concrete operational stage did not fulfill Piaget's logical operations, as shown by their failure to solve mathematical problems in the TLO in math, according to the findings. Instructors and professors in college mathematics and science can no longer believe that all fourth-year students are already in the formal operational stage of cognitive growth. This means professors must be mindful that students may be unable to solve simple to complex math problems. Since mastery of cognitive skills is required to achieve the twin goals of mathematics education in the $\mathrm{K}-12$ curriculum, it is highly anticipated. Math teachers must build a learning atmosphere, develop teaching methods, and engage students in various learning materials that develop logical-mathematical processes and encourage cognitive skills because students have been found to have an inadequate understanding of certain logical thoughts. Teachers must adapt their instruction to their students' cognitive demands and levels of cognition. Teachers in basic education should concentrate on the learners' cognitive growth because their cognitive skills and critical thinking abilities are only beginning to improve at this age.

\section{REFERENCES}

1. Salangsang, L. \& Subia, G. (2020). Mathematical thinking on problem-solving and self-

a. regulation strategies of Filipino primary grade pupils. International Journal of Scientific \& Technology Research, Vol.9, Issue 2

2. Subia, G., Marcos, M., Valdez, A., Pascual, L. \& Liangco, M.(2020). Cognitive Levels as Measure of HigherOrder Thinking Skills in Senior High School Mathematics of Science, Technology, Engineering, and Mathematics (STEM) Graduates. Technology Reports of Kansai University. Volume 62, Issue 3, pp 261 268.

3. Inhelder, B. and Piaget, J. (1958). The Growth of Logical Thinking from Childhood to Adolescence. Retrieved February 08, 2018 from http:/psychology.about.com

4. Scriven, M. and Paul, R. (1987). Critical Thinking as Defined by the National Council for Excellence in Critical Thinking. A statement at the 8th Annual International Conference on Critical Thinking and Education Reform, Summer 1987. Retrieved March 8, 2018 from http://www.criticalthinking.org/pages/definingcritical-thinking/766

5. Alcantara, E. C. and Bacsa, J. M. P. (2017). Critical Thinking and Problem Solving Skills in Mathematics of Grade 7 Public Secondary Students. Asia Pacific Journal of Multidisciplinary Research 2017, 21-27

6. Sternberg, R. J. (1986). Critical thinking: Its nature, measurement, and improvement. National Institute of Education. Retrieved March 9, 2018 from http://eric.ed.gov/PDFS/ED272882.pdf.

7. Subia, G. S. Treasure Chess: Worthy Contributions of the Game in the Lives of Student Champions. The Normal Lights, (2020), 14(1):100-121

8. Polya, G. (1980). 'On solving mathematical problems in high school'. In S. Krulik (Ed). Problem Solving in School Mathematics, (pp.1-2). Reston, Virginia: NCTM.

9. Keen, R. (2011). The Development of Problem Solving in Young Children: A Critical Cognitive Skill. Annual Review of Psychology, Vol. 62: 1-21

10. Piaget, Jean. (1950). The Psychology of Intelligence. New York: Routledge. Retrieved March 8, 2018 from http:/www.webspace.ship.edu

11. Inhelder, B. and Piaget, J. (1967). The Early Growth of Logic in the Child, Classification and Seriation. Retrieved February 08, 2018 from http:/psychology.about.com

12. Gamit, A. M. (2010). Cognitive Skills Achievement in Basic Mathematics of College Freshmen in Selected State Universities in Region III. Dissertation. Ph.D. Mathematics Education, Nueva Ecija University of Science and Technology, Cabanatuan City

13. Allen, M. B. (2010). Improving State Need Assessments of Secondary Science and Mathematics Teachers: Challenges, Possibilities, and Recommendations. Retrieved March 16, 2017 from http://www.aplu.org

14. Calderon, J. F. \& Gonzales, E. C. (2016). Methods of Research and Thesis Writing. National Book Store, 2016

15. Ariola, M. M. (2006). Principles and Methods of Research. Rex Book Store, Inc.

16. Schoenfeld, A. H. (1982). Measures of Problem Solving Performance and of Problem Solving Instruction, pages 31 - 49. Retrieved February 8, 2018 from https://www.jstor.org

17. Bruner, J. S. (1961). The Act of Discovery. Harvard Educational Review 31 (1): 21-32. Retrieved March 8, 2018 from http://tip.psychology.org/bruner.html 
18. Pagay, A. M. (2008). An Investigation of the Cognitive Skills Achievement of Selected Pre-Service Mathematics Teachers. Dissertation. Ph.D. Science Education (Mathematics). De La Salle University, Manila

19. Domingo, J. G. (2018). Cognitive Skills Achievement of Senior High School Pre-Baccalaureate Maritime Students in Mathematics and Its Determinants: An Evaluation Using Piaget's Logical Operations. A paper presented at the 1st Luzon-wide Senior High School Research Congress, Tuegagaro City

20. Raven, R. (1973). The Development of a Test of Piaget's Logical Operations. Journal for Research in Science Education. 377-385.

21. Leongson, J. A. \& Limjap, A. A. (2003). Assessing the Mathematics Achievement of College Freshmen Using Piaget's Logical Operations. A paper presented at the Hawaii International Conference on Education, Waikiki, pp. 1-25

22. Decano, R. S. (2017). Cognitive Development of College Students and Their Achievement in Geometry: An Evaluation Using Piaget's Theory and Van Hiele's Levels of Thinking. American Journal of Applied Sciences, 14(190), $899-911$ 